\title{
ARTÍCULOS
}

\section{EL DERECHO AL TERRITORIO COMO BASE DE LA JUSTICIA COGNITIVA*}

\author{
RIGHT TO TERRITORY AS A BASIS FOR COGNITIVE JUSTICE
}

\author{
Beatríz Nates-Cruz ${ }^{1}$ \\ Universidad de Caldas, Colombia
}

Recibido: 11 de abril de 2018; Aprobado: 28 de marzo de 2019

Cómo citar este artículo / Citation: Nates-Cruz, Beatríz. 2020. «El Derecho al territorio como base de la justicia cognitiva». Disparidades. Revista de Antropología 75(1): e004. doi: <https://doi.org/10.3989/dra.2020.004>.

RESUMEN: El derecho al territorio no es un asunto meramente jurídico, es, sobre todo, un argumento cultural de la conducta socioespacial que da concepto, regulación y establecimiento a las relaciones sociales. Este artículo sitúa el derecho y la justicia como categorías explicativas, en la medida en que permiten establecer, en nuestro caso, etnográficamente, los factores que orientan su producción y reivindicación a través de hechos que dan cuenta de una sociedad, de su geografía y de su historia (hechos territoriales). La justicia a la que hacemos referencia es cognitiva, por ello se entiende, un conjunto multidimensional de conocimientos situados (o de lugares que producen conocimientos) para el saber estar. El presente artículo abordará esta postura a partir de dos investigaciones desarrolladas en distintos proyectos realizados entre 2011 y 2017 en los Andes Centrales de Colombia, bajo los temas: «escenarios de postconflicto en Colombia» y, «reconfiguración antropoecoambiental». Las tecnologías y materiales culturales que presentamos están en el ámbito de las escalas territoriales desde un análisis de la antropología del territorio.

PALABRAS CLAVE: Derecho; Territorio; Justicia cognitiva; Andes de Colombia.

ABSTRACT: The right to territory is not purely a legal matter. It is above all, a cultural argument of socio-spatial behaviour that gives concept, regulation and establishment to social relations. This article positions law and justice as explanatory categories, insofar as they allow us to establish - in our case ethnographically - the factors that guide their production and vindication through facts that account for a society, its geography and its history (territorial facts). The justice to which we refer is cognitive, which involves a multidimensional body of situated knowledge (or places that produce knowledge) for knowing how to be. This article

* El artículo se basa en los proyectos: 1. «Procesos de territorialización de la memoria en escenarios de postconflicto. Caracterización, implicación y lineamientos de políticas en el orden local, regional y nacional» (Proyecto TEMPO), financiado por CNMH y COLCIENCIAS; 2. "Escenarios de postconflicto en Colombia 2005-2010. Estudio de las representaciones culturales e implicaciones sociales en municipios tipo", financiado por la Universidad de Caldas; 3. "Vulnerability and adaptation to climate extremes in the Americas» (Proyecto VACEA), financiado por el Gobierno de Canadá, proyecto en red Américas; 4. "Cartografía semiótica para la comprensión, análisis y monitoreo del Paisaje Cultural Cafetero como Patrimonio de la Humanidad» (PCCCaldas). El caso de Caldas, financiado por la Universidad de Caldas, Colombia.

1 Profesora Titular (ICSH, GIT, ANTROSOC/RETEC/ELER/CNPT). Correo electrónico: beatriz.nates@ucaldas.edu.co. ORCID iD: <https://orcid.org/0000-0002-3246-7903>. 
will address this position on the basis of two investigations carried out in the Central Andes of Colombia between 2011 and 2017, under the themes: "post-conflict scenarios in Colombia" and, "anthropo-environmental reconfiguration". The technologies and cultural materials presented fall within the scope of territorial scales (scale as cultural value) from an analysis of the anthropology of the territory.

KEYWORDS: Law; Territory; Cognitive justice; Andes of Colombia.

Copyright: (C) 2020 CSIC. Este es un artículo de acceso abierto distribuido bajo los términos de la licencia de uso y distribución Creative Commons Reconocimiento 4.0 Internacional (CC BY 4.0).

\section{INTRODUCCIÓN}

El territorio se produce a partir del conocimiento del mundo que tiene la gente, del que tienen de ella misma, de su entorno, de sus datos, de sus actos y de las cosas que los rodean.

El debate entre derecho y justicia tiene largo aliento, pero lo que aquí se expone y analiza se ubica en lo que señala Priscilla Claeys (2016) acerca de que el derecho al territorio debe tratarse como un nuevo derecho humano y como un marco de acción colectiva. En Colombia existen textos que tratan el tema, entre los que están Coronado Delgado (2006), el ClNEP (2009), la Comisión Nacional de Reparación y Reconciliación (2009), Rodríguez (2010), la Comisión Colombiana de Juristas (2011), Martínez Calderón (2014) y Bocarejo Suescun $(2011,2015)$. El enfoque de estos estudios es jurídico o económico y, sobre todo, en el marco de los pueblos indígenas (Convenio 169 de la OIT) o afrocolombianos. En otros textos se desarrolla el tema en diálogo con el derecho a la tierra (Nates 2016a, 2016b; Nates, Velásquez y García 2018), pero no directamente como base de la justicia cognitiva. Sobre el impacto de la cultura y el conocimiento cultural en sociedades no etnizadas, poco se dice (o se legitima) cuando se habla de la relación derecho al territorio y del conocimiento situado.

Los estudios sobre el derecho al territorio requieren, entonces, de una discusión más fina que ligue la conducta socioespacial a los hechos territoriales y no se reduzca solamente a la identidad. Tal ligazón podría producirse si asumimos que el derecho participa del conjunto del sistema normativo de una cultura dada $y$, por tanto, conviene estudiarlo a partir de las territorialidades de distintos dominios de la vida social, política, religiosa, simbólica y económica (Verdier 1981). Se requiere dar visibilidad al sistema de ideas y de valores que, en suma, son la base del sistema de derecho (Verdier 1981) o, como diría Ignatieff (2018), se requiere hacer visibles las virtudes cotidianas o la geografía de la civilidad (Nates 2016a, 2018a, 2018b). Y también como lo señala Barreaud (2013), es importante tener en cuenta las nuevas dinámicas globales de migración y movilidad, donde el derecho al territorio se reclama sobre territorios «no situados» que se «cargan consigo mismo». Este fenómeno exige de los investigadores territorialistas agudeza conceptual para atrapar y dar cuenta del fenómeno, en el marco de lo que él autor llama, la postmodernidad jurídica.

Los conceptos matriz de dicho derecho al territorio son el territorio, la justicia y la justicia cognitiva. Por territorio entendemos el producto de una relación entre la geograficidad (relación fisiografía/sociedad), la sociabilidad (relaciones de fuerza y de sentido), la historicidad (los ritmos y los momentos) y la políticaemocionalidad $^{2}$. Proponemos, con Mate (2011), Massey (2005) y Young (2011), leer la justicia en términos de responsabilidad sobre causas materiales, morales, éticas y simbólicas. De acuerdo con esto, la justicia cognitiva constituye la responsabilidad sociocultural interna y externa sobre el conocimiento situado para actuar sobre el ordenamiento vital y social (Nates, Velásquez y García 2018; Nates 2018c, 2019). Este conocimiento situado implica, en términos de la justicia cognitiva, hacer legible quién habla y hacer visible el lugar desde dónde habla como geografía y como inclusión sociocultural (condición, género, generación). Esto exige la participación del investigador, o aquello que Bourdieu (2003) llama la objetivación participante que, en perspectivas conexas, podemos llamar con Haraway (1997) conocimiento co-construido.

\section{II}

En 2016, durante un trabajo de campo al Este del Departamento de Caldas, un funcionario de uno de los ayuntamientos de esos municipios expresó que la

2 Documento Maestro del Doctorado en Estudios Territoriales, Universidad de Caldas Colombia (2011, 2016). 
razón por la cual no viajaba a una vereda ${ }^{3}$ llamada Samaria, con el fin de verificar cuál era la situación sobre la tenencia de tierra y su restitución en el marco de la Ley de Víctimas y Restitución de Tierras (Ley 1448 del 10 de junio de 2011), estaba en que "ahora quedaba muy lejos [del casco urbano del municipio]». En el año anterior un maestro de otro municipio que se ubica al Norte del mismo Departamento refería: «ahora la escuela queda muy lejos [...]. Como ya no hay niños y pastan las vacas dentro de los salones, ya eso es muy enredado ir allá, queda ahora muy lejos, no vale la pena ir a contar un niño nada más».

Esta lejanía no solo está dada por la apariencia miserable de un lugar o por su lejanía fáctica, sino que está determinada por la distancia simbólica de la gente de allí, que no es urbana o que "no es como uno». Esta actitud revela una segregación socioespacial que aleja cualquier lugar en estas perspectivas.

Esta marca de distancia espacial que como imágenes y postura son recurrentes en los proyectos de investigación, nos llevaron a entrar en el análisis de las escalas territoriales como eje de la relación entre el derecho al territorio y la justicia cognitiva.

Se ha vuelto tradición y cada vez con más fuerza, no solo gubernamental, sino también científica, que sea el desarrollo económico territorial, impuesto como modelo de la concepción y ordenación territorial a comienzos del siglo $\mathrm{XX}$, lo que determine los parámetros para ubicar pueblos, veredas, pedanías y ciudades; bajo la lógica de lo que la geografía económica reduce a las escalas de la distancia, la división y la densidad, que son asumidas como la única forma o, al menos, la forma legítima de pensar el territorio.

Conforme a esta lógica, la ubicación o existencia de un territorio se pondera: 1. En distancia, según qué tan cerca o qué tan lejos esté un lugar de un centro administrativo gubernamental (cabecera municipal); 2. En densidad, según cuántos habitantes tenga continuidad en uno de los estatus de la ordenación del territorio (municipio corregimiento, pedanía, ciudad...) y, con ello, la transferencia de recursos; 3. En división, según cómo, a partir de las otras dos escalas, cuente el lugar de mayor o menor importancia municipal, regional o nacional, lo que lo pondera tam-

3 Vereda y corregimiento son figuras de organización territorial en Colombia. Un corregimiento se compone por veredas y ese conjunto forma parte de un municipio. bién por los recursos que produzca y, por tanto, por los impuestos percibidos.

De cómo el fenómeno de esta forma de «contar el mundo» se ha vuelto un problema se han ocupado, más que la antropología, la politología o la geografía política y cultural. En antropología quizá lo evocan los estudios clásicos de Lévi-Strauss (1998) o los más recientes de Rapapport (2000), Hayot (2004), Rousseaux y Petit (2014), entre otros. Un buen ejercicio por abordar el tema de las escalas más de cerca es el trabajo de la antropóloga Berardi-Tadié (2017). Sin embargo, consideramos que es la politóloga Nancy Fraser (2008) quien hace una propuesta novedosa que nosotros utilizamos para debatir o complementar esa escala de las tres $D$ que acabamos de mencionar (distancia, división, densidad). Ella refiere las escalas de la representación, el reconocimiento y la redistribución (tres R) como escalas de justicia, y nosotros desde allí las denominamos escalas como valor o escalas culturales. Según Fraser (2008), el reconocimiento y la redistribución deben ir juntos, no obstante, cada uno, al igual que la representación, ocupa campos de definición teórica y de uso político preciso.

Para explicar lo que entendemos por representación tomamos una frase del conocimiento nativo, "somos nosotros los de aquí», lo que sitúa el concepto en un posesionarse y en una posición por la identidad como responsabilidad. Por reconocimiento acudimos a la frase, "nos sabemos nosotros mismos» para indicar que antes que mirar hacia afuera, reconocerse es saberse en sí mismo (colectivo o individual, mujer, hombre). La redistribución no solo es económica, es, como dicen los nativos andinos «repartir las cargas». Cargas en el sentido de asignar, de endosar, de entregar o de recibir un don y un contra-don que en nuestros estudios observamos pasa de manera predominante por la tenencia de la tierra, pero cuyo proceso no se puede entender sin que medie la legitimación de lo simbólico y lo cultural: no es cualquier tierra, es la finca, la huerta, la vereda, el pueblo; no es a cualquier persona, es "uno de aquí». Esta forma de entender la redistribución va desde la producción material misma hasta el affection home.

La conexión entre el derecho al territorio y la justicia cognitiva exige esa nueva lectura escalar entre las tres $D$ y las tres $R$, que permita influir con postura en la toma de decisiones conceptuales y políticas, bajo criterios y apreciaciones de alternativas para un discurso practicado y un discurso vivo. Interrogarse 
sobre a quién le sirve el conocimiento situado (Harawey 1995; Braidotti 2005; Novoa 2016) contribuirá al debate de una justicia cognitiva puesta en hechos, situaciones, objetos y lugares "georeferenciados».

\section{METOdOLOGÍA}

La metodología utilizada en las investigaciones fuente de este artículo fueron la cartografía cognitiva - cartografía a mano alzada de las situaciones problema; las filmaciones, los paisajes sonoros, la cartografía SIG-interactiva con fotografía y vídeo, la cartografía de sintaxis espacial; los talleres de conocimiento, los conversatorios domésticos, las entrevistas abiertas y a profundidad y el debate local con actores sociales comunales y gubernamentales; las observaciones directas e indirectas y los diarios de campo como recurso epistemológico registrado en reuniones; la exposición de imágenes y objetos, así como las reflexiones in situ y ex situ del trabajo de campo. El análisis se hizo con lecturas de contexto en las que se entreveraron actor social-situación vivida-trayectoria local y nacional del fenómeno o problema referido en la entrevista; las infografías y cartografías se analizaron desde el punto de vista semiótico con-sentido de las entrevistas analizadas en los programas informáticos NVIVO e HyperRESEARCH, y, desde el punto de vista del concepto, se realizaron análisis a través del modelo comprensivo que implica dimensiones, variables (cualitativas y cuantitativas) e indicadores (cualitativos y cuantitativos).

\section{DERECHO Y COGNICIÓN}

Los juristas contemporáneos afirman que el derecho al territorio está en el marco o bien de un nuevo territorio o bien de una multiplicación de territorios en los cuales la identidad y la autonomía no cesan de afianzarse. En esa postura, el concepto de identidad no evoca, en ningún momento, el de conocimiento territorial y, por tanto, tampoco implica la legitimación del sentido de pertenencia a un lugar que tiene un actor social o una colectividad.

En Colombia existe una disyuntiva, que va más allá de lo formal, entre dos conceptos. Remitámonos a lo que se asienta en la Ley de Víctimas y Restitución de Tierras que hemos citado al comienzo: restitución de tierras y restitución simbólica. Nótese el doble vínculo de la palabra restitución asociada, de una parte, a un asunto fáctico (tenencia, uso y gestión de un lugar, eso implica en la Ley restitución de tierras) y, de otra, a un asunto definitivamente cultural como lo simbólico (restitución simbólica). No obstante, el Estado ha soslayado lo que implica en el fondo la palabra «restitución» y algunos académicos han referido sobre todo a la tenencia de tierra como lo expresan, por ejemplo, los trabajos de Sánchez León (2017), Bolívar Jaime, Sánchez León y Uprimny Yepes (2017), Bolívar Jaime, Botero Giraldo y Gutiérrez Baquero (2017), Martínez-Calderón (2014), Pérez Trujillo y Landínez Aceros (2018) y Rincón (2017).

A continuación, abordaremos todo el marco que venimos dando, a través de los proyectos citados ${ }^{4}$ en sus siglas, TEMPO, VACEA y PCC en Caldas Colombia. En el caso de lo que se denomina tierra y simbólico, las colectividades locales de campesinos reclaman en Colombia una restitución situada en la que, de una parte, no se reduzca la tierra solo a lo fáctico mediante la propiedad y que, de otra, no se reduzca lo simbólico a festivales, torneos deportivos o ferias, cuestiones en las que ha puesto el énfasis el gobierno cuando de "restitución simbólica» se trata. Este reclamo lo registramos así en el proyecto TEMPO:

\begin{abstract}
Una restitución simbólica de la finca como el microcosmos que en lo rural hace sentido del ser, del tener y del estar. De la vereda que hoy más que nunca se ha visto que en Colombia no solo funge como el hábitat por excelencia en el campo, sino como la territorialización más eficaz al momento de hablar de instaurar en el campo los posacuerdos con la guerrilla de las FARC (23 de junio de 2016), mostrando la injusticia espacial con que ha sido tratada como concepto y unidad territorial en la historia del país. De la casa como la transición entre la vida de todos los días y la institucionalidad de la vida cotidiana para incorporar la cultura. De la escuela como el lugar donde se produce la concreción entre la memoria individual y colectiva que sustenta la historia de un país. Del pueblo mismo como una figura no solo diacrónica descriptiva, sino como una referencia a la relación espacio, gente y proyecto futuro. El pueblo como un medio humanizado, a la vez producto y sustancia activa de sociedades localizadas (Proyecto TEMPO. Informe final, junio de 2017).
\end{abstract}

4 Ver proyectos en nota inicial del artículo. 
De la cita del informe consideramos resaltar la conexión socio-espacial entre finca, vereda, escuela y pueblo. Son a la vez metáforas del «buen vivir» y materialidades de la relación gente y proyecto futuro. Son la muestra del ser, tener y estar, que durante el conflicto armado permitió a los nativos desarrollar a través de ellas, estrategias y mecanismos de conocimiento local como insumos de resistencias particulares (faire face), y que hoy, bien podrían orientar modelos de justicia para apoyar alternativas de una seguridad territorial en escenarios de postconflicto.

A nivel global existen posturas evocadoras que relacionan el derecho al territorio con el conocimiento. Sin embargo, a menudo, estas posturas se reducen a circunscripciones político administrativas, lo que genera volver sobre la imagen de escala como grado de la geografía económica (distancia, división, densidad). Las publicaciones que hemos rastreado o se enfocan en lo rural, desde la tenencia de tierra como medio de producción o de legitimidad étnica, o se sitúan en la ciudad con un fuerte vínculo al concepto de ciudadanía lo que deja por fuera el campo (Léfèbvre 1975; LVC 2012; Haesbaert 2011; Harvey 2013; Right to the City Platform $2018^{5}$ y Fernandes 2008a, 2008b, 2009 , entre otros). En esta dicotomía el pueblo como territorio (según lo que hemos planteado que define este concepto) queda, por ejemplo, como comodín de quien lo incluya como rural o como urbano.

Y también otras que conectan el Estado con el Derecho al Territorio. El derecho al territorio completa su reclamo y su consumación en el «derecho al Estado", dicen Martin y Renaudie (2017), donde el primero es corolario del segundo. El derecho al territorio en esa perspectiva no solo compete al reconocimiento de lo nuevo o existente, sino también al sostenimiento multidimensional de un territorio (entendido este como el concepto definido a lo largo del artículo). Desde el punto de vista sociopolítico, dicen Martin y Renaudie (2017), el derecho al territorio se desprende de las realidades producto de la multiplicación de territorios en los cuales la identidad y la autonomía no cesan de reforzarse.

Si de otra parte retomamos al académico brasileño Bernardo Mançano Fernandes (2009), podemos compartir la definición de territorio que relaciona lo ma-

5 Right to the city platform 2018. Disponible en: <http:// www.righttothecityplatform.org.br/?lang=es $>$. Fecha de acceso: 10 feb. 2018 terial y simbólico; no obstante, marcamos diferencia cuando hace divisiones tan tajantes. Para este autor hay una división entre territorio inmaterial y territorio material. Dice que el territorio inmaterial son ideas, paradigmas y explicaciones, sobre el territorio material que es lo fáctico, lo económico. Sostiene que las disputas territoriales parten de esas diferencias intelectuales. Nos distanciamos, sin embargo, de esta postura, en la idea de territorio inmaterial y material porque, aunque el autor asume que van juntos, no se trata de que cada uno esté en una esfera diferencial de producción de conocimiento o del modelo de clases y sus relaciones, lo que acontece en lo urbano, lo rural o lo rururbano es producto de relaciones de geograficidad, sociabilidad, historicidad y políticoemocionalidad $^{6}$ que producen la conciencia de sí, del ser y del tener, de una parte, y las estructuras socioespaciales como espacios de mesura y de acción que hacen que la pertenencia se transforme gradualmente en apropiación y que esta se transforme casi sin darse en cuenta en pertenencia. En consecuencia, la cognición, en términos del conocimiento intelectual local o académico, no es un mundo aparte que obra sobre el territorio como contenedor de relaciones, es lo que lo produce, es lo que lo hace trascendente, es lo que le da legitimidad y continuidad desde las condiciones y perspectivas de quien lo produce y de cómo se produce.

Este conocimiento situado se objetiva en el saber para y desde el entorno con ejercicios culturales que van desde vivir, discurrir o constatar la existencia del territorio, hasta llegar a producir desde y con él. Todo esto se ha puesto en evidencia en las investigaciones que soportan este artículo, veamos.

En el trabajo de campo de 2016 (Proyecto VACEA) en la Cuenca del río Chinchiná, Caldas Colombia (La Nueva Primavera), evidenciamos la importancia de un grupo de mujeres que en número no son significativas, pero que, en el rol del conocimiento climático para la mina de río, trabajo que realizan los hombres, son fundamentales.

Los hombres esperan a que estas mujeres llamadas "gariteras» y «bogueadoras» (o "boguiadoras») les lleven alimento y bebidas al lecho del río donde se ubican desde la aurora, para sacar materiales que luego venden a las constructoras; pero, además de comida y bebida, esperan que les informen lo que

6 Ver definición de estos conceptos más arriba. 
vieron en el trayecto camino al río: arrastre de rocas, presencia de gravilla, intensidad del caudal aguas arriba. Ellas caminan en torno a $10 \mathrm{~km}$ desde sus casas en ida y regreso hacia la mina del río (su vereda se ubica a 1600 m s. n. m. ${ }^{7}$ ) y llevan informaciones sobre la densidad del agua, tono de la misma, profundidad del río que estas mujeres miden con varas y bastones, que marcan cada día para tomar las medidas de longitud, más que con métrica, con sentido común. Ellas saben "cuánto bajó o cuánto subió el agua al borde del camino». Estas mujeres garantizan el éxito del trabajo del grupo de mineros de río que se autodenominan "los combos», pero como vemos no solo mediante el alimento (gariteras) y la hidratación (bogueadoras), sino porque «les llevan conocimiento» del "tiempo que hace» en el recorrido del río, lo que les permite a los mineros no solo proyectar el tipo de materiales que sacaran cada día, la cantidad y la calidad, sino, además, prever, a partir de la información recibida, el estado del tiempo para organizar las faenas diarias del trabajo minero.

Las gariteras y bogueadoras, mujeres campesinas de entre 20 y 50 años, jefes de casa y de familia que a veces se hacen acompañar por sus hijos pequeños en estas actividades, han acumulado y gestionan un conocimiento en técnicas y conceptos que les da el poder de saber cómo es y cómo ha evolucionado un lugar que monitorean con cuidado de generación en generación en el trabajo de mina de río.

A la fecha (2016), estas mujeres cumplen, además, la labor de "vigías naturales» que no solo contribuye al éxito del trabajo de los mineros, sino que también, como valor agregado, consiste en la vigilancia para que el río no sorprenda con desbordes porque recuerdan que el lugar en el que viven, La Nueva Primavera, es un reasentamiento producto de la avalancha en los Andes Colombianos del Nevado del Ruiz de 1985. Este trabajo las mantiene alerta con el valor de la memoria que les recuerda que si el "río brama», como lo dicen, deberán advertir a todos porque viene lava de volcán. Esta es una región de volcanes y de montaña que ha convivido con temblores y avalanchas en ciertos periodos, y cuya neblina cobija con frecuencia la montaña. Por ello, el trabajo de llevar comidas y bebidas durante todo un día, seis días a la semana, ha desarrollado esta "profesión» de climatólogas locales, sin las cuales, sería imposible hacer

7 Metros sobre el nivel del mar. cualquier estudio de territorialización climática en la zona. Ellas lo refieren así:

\begin{abstract}
Aquí los que cuentan son los combos [mineros] que manejan las minas de arena del río. Y nosotras las gariteras, no contamos porque tengamos plata pa [para] aportar en necesidades o fiestas como ellos, pero somos las que conocemos todo lo que aquí pasa. Llevamos 3 y 4 veces las comidas a los trabajaderos, son como 6 veces entre que vamos y venimos, nos damos cuenta de todo. Pero también sin las comidas ellos no comen y nosotros tampoco, porque nos pagan a 4 mil pesos comida llevada. En otras partes más arriba [en veredas hacia la montaña] están también las boguiadoras, esas van más porque llevan la bebida, sino ¿cómo boguean [cómo se hidratan] pa todo lo que hay que trabajar? Ellas se dan cuenta de más cosas: si llueve, si llega alguien nuevo, aquí ellas son como una cajita de conoceres [cajita de conocimiento] (Extracto de entrevista a Mónica Gómez, garitera de la vereda La Nueva Primavera, Villamaría, febrero 2016. Proyecto VACEA).
\end{abstract}

Muchas de estas mujeres no son dueñas de la tierra, pero son dueñas del territorio, tienen un sentido del lugar que les da el conocimiento que tienen de él, todo el derecho territorial de ser y de estar allí, en la vereda. Por sobre otros roles de gentes del lugar, son ellas quienes dan cuenta del clima. Ellas caminan largos trayectos y dan cuenta de si las nubes «están negras» y habrá tempestad, saben del clima y sus transformaciones territoriales más que cualquier agricultor que está en lo suyo propio o que un minero de río que solo sabe si el río está «bendito» o «maldito» un día u otro, dependiendo de los materiales que traiga y que ellos le extraen.

En otra parte del mismo departamento de Caldas, hacia el Oeste (alto Occidente) y bajo un problema territorial diferente, pero en el mismo marco de nuestro análisis o en equivalencia, podemos citar lo que encontramos entre los indígenas del municipio de Ríosucio. Allí y a la manera de las rogativas, rituales recurrentes en otros lugares de América Latina y que aún subsisten en España, pero en nuestro caso, no con santos que se llevan de casa en casa, o por veredas y pueblos, sino con una población nativa que se moviliza ella misma para lograr en persona el efecto deseado donde hiciera falta, los indígenas embera chamí de este municipio, enfrentaron el periodo más cruel de la guerra (desde 1990 hasta 2010) entre guerrilla, paramilitares y Ejército Nacional con un faire face, que les implicó recurrir a todos sus materiales 
cognitivos, emocionales y políticos para salir adelante como pueblo:

Decidieron realizar un recorrido directo por los corredores de guerrilla y paramilitares al que denominaron andar territorial. Este fue convocado por los indígenas para hacer un recorrido por todos los caminos de los cuales se habían apropiado, tales como corredores paramilitares y guerrilleros, para hablar directamente con estos grupos y para desterritorializar desde dentro esa legitimidad violenta y reapropiarse de lugares que habían sido históricamente recorridos por los indígenas y mestizos para transportarse y transportar sus productos. Comenzar por reapropiarse de los caminos constituyó un símbolo políticamente central como estrategia de postconflicto armado, puesto que los caminos y las sendas eran, para los locales, los lugares desde los que habían hecho suyo un territorio y a partir de los cuales habían trazado redes parentales, económicas y sociales de todo orden. Este era un andar político que les permitía, aunque con temor, hacer frente directamente a una situación que desbordaba cualquier posibilidad de vida (Personera del municipio de Ríosucio. Trabajo de Campo, Foro de Localidades Postconflicto, Manizales julio 2011. Proyecto, Escenarios de postconflicto en Colombia 2005-2010. Estudio de las representaciones culturales e implicaciones sociales en municipios tipo).

Pero también hubo para este ánimo de rogativa territorial en Ríosucio, un hecho político muy fuerte, tal como lo muestra la personera ${ }^{8}$ del municipio, situación ante la cual, la población no encontró otro medio más autónomo que su andar territorial:

A nivel nacional no había una política clara y debíamos improvisar todo. Un día me dijo el Defensor del Pueblo: "váyase y detenga el desplazamiento» y al llegar vi de qué se trataba y ientendí que el gobierno no entendió nada! Luego nos llamaron y nos dijeron: «llévennos a hablar con los violentos, llévennos a la zona de conflicto". Y nosotros los llevamos y cuando nos los encontramos y esos funcionarios se bajaron a frentearlos [hacerles frente], fue horrible y peligroso, que peligro en que nos pusieron [...]. No entendían nada, todo lo veían desde el escritorio, era como si estuviéramos puestos en realidades totalmente distintas y quizá así era, pero ellos eran responsables. Nosotros, al ver

8 Personero en Colombia es un adjunto jurídico de las alcaldías que representa a la comunidad y se encarga permanentemente de ejercer la defensa de los derechos; recibe las quejas que presenta cualquier persona sobre las situaciones violatorias de los Derechos Humanos e informa a las autoridades competentes sobre los hechos. una y otra vez actitudes como estas, decidimos pensar qué hacer y cómo seguir manejando el asunto (Personera del municipio de Ríosucio. Trabajo de Campo Foro de Localidades Postconflicto. Manizales, julio 2011. Proyecto, Escenarios de postconflicto en Colombia 2005-2010. Estudio de las representaciones culturales e implicaciones sociales en municipios tipo).

Los trabajos de campo referidos traen consigo la ponderación de las escalas de la representación y del reconocimiento para la redistribución. La redistribución en las escalas remite al ejercicio de un don y contra-don en el marco de la misma oportunidad de paridad territorial, no solo en el plano de lo económico como intercambio material fáctico, sino también en el intercambio material que sustenta lo simbólico. La redistribución es la escala de mayor fuerza territorial por ser la escala que consuma la justicia de las tres «R», esto es, la justicia cognitiva; pero, sobre todo, lo es por ser una escala desde la cual podemos constatar cómo, desde dónde y con qué se impacta un conocimiento compartido o denegado, en la distancia de las alteridades o en la aproximación de las mismidades, en el corpus cultural que estamos dispuestos a aceptar o a defender, como enmarque o desenmarque de reclamos y reconocimientos, para legitimar la redistribución fáctica o simbólica del lugar de cada uno, de los otros y de los mismos en un territorio determinado.

Estos datos de trabajo de campo están, no obstante, en una línea del derecho, es decir, cuando la población está en relación de inequidad y desventaja y demanda dicho derecho. Pero ¿qué sucede cuando quien demanda son aquellos que históricamente han tenido la tierra y el territorio? Esta situación la hemos abordado también en un trabajo de campo en el marco de la relación cultura-paisaje productivo.

En el año 2013 tuvo lugar en Colombia lo que se conoce como paro cafetero, o huelga cafetera. En este momento, todos los municipios colombianos productores de café salieron de todos los rincones del país a un plantón que duró varias semanas al que se unieron otros sectores productivos del país ${ }^{9}$, salieron en manifestaciones sobre las vías principales de las ciudades y, sobre todo, en carreteras, en particular, en la carretera central de este país, la Panamericana.

9 Para ampliar la información sobre el paro cafetero, se sugiere ver: <http://www.semana.com/nacion/articulo/paroagrario-las-dos-caras-de-la-protesta/>. 
Esas manifestaciones se instalaron con tiendas de campaña, con arengas y confrontaciones entre la policía antidisturbios y las organizaciones de campesinos y los productores no afiliados tenedores de tierras productivas en café. Pues bien, en ese marco, la mayor extrañeza social que se produjo fue la supuesta falta de participación de algunos sectores de grandes finqueros del departamento de Caldas, lugar preponderante en la producción histórica del grano. Sin embargo, así lo registramos en campo:

No entren, gritó una señora [...] Si Ustedes son de esos de la Nacional [Universidad Nacional de Colombia] que nos desprestigiaron en twitter, no entren [...]. No, le respondí, somos de la Universidad de Caldas [...], soy la coordinadora de un proyecto. Nos miró desconfiada y como llorosa y le indicó al mayordomo que nos dejara pasar a un pequeño salón de la finca-hacienda. Una vez allí, nos dijo llorando: "los de la Nacional dijeron que no estábamos comprometidos con el paro cafetero [manifestación o protesta nacional de los cafeteros] porque no habíamos salido a manifestarnos a la carretera [...] y como le dije a Humberto: -Cómo vamos a ir, sino distinguimos un policía del ESMAD [policía antidisturbios], de un patrullero [policía de tránsito], no sabemos qué es una papa bomba, no sabemos cómo se debe poner uno, si hay que correr a la izquierda o a la derecha, adelante o atrás, no sabemos cómo participar de una manifestación. Uno las ve en la televisión, pero no es lo mismo que le toque a uno, sería necio participar en eso. Aquí en esta región [Caldas] no hay tradición de marchas, si uno va, lo salen matando y con razón, por torpe, por no saber de eso [...]. Pero eso no quiere decir que no hayamos participado: dimos cobijas [mantas], medicamentos, comida, recogimos por aquí y les hicimos llegar a la carretera, eso también es participar, unos en la calle y otros haciendo las cosas adentro, pero eso no lo vieron, solo dijeron que nos hicimos los locos con el compromiso y eso me duele porque nosotros aquí en la Gaviota hemos hecho un esfuerzo muy duro para seguir con el café a pesar de las crisis (Retomado del Diario de Campo. Entrevista a Carolina dueña de la Finca La Gaviota. Chinchiná, abril 2013. Proyecto Cartografía semiótica para la comprensión, análisis y monitoreo del Paisaje Cultural Cafetero como Patrimonio de la Humanidad. El caso de Caldas).

En otro momento, en el mismo proyecto (septiembre 2013) fuimos a otra vereda a entrevistar a una líder y cuando hicimos referencia a la entrevista de la finca La Gaviota (entrevista anterior) nos dijo lo siguiente:
Es verdad, nos dijo. Nosotros cómo vamos a participar, si no sabemos movernos en eso [...]. Yo le digo con confianza, en vista de que parece ser que solo moviéndonos así nos hacen caso, entonces llamamos a un especialista de esas marchas [...] y nos capacita por las noches para saber cómo participar de las manifestaciones. Nosotros no queremos conflicto, ni aprender malas cosas, pero tenemos derecho a aprender cómo se hace, cómo es que uno se pone en la acción y así, si es necesario salir a la carretera. Esa persona nos indica como es "delante", "atrás", "a los lados" y nos indica cómo saber si se ha metido gente mala en la marcha [infiltrados] [...]. Por ahora nosotros participamos dando apoyo logístico, digamos, damos mercado o así (Retomado del Diario de Campo. Entrevista $10^{10}$. Chinchiná, abril 2013. Proyecto Cartografía semiótica para la comprensión, análisis y monitoreo del Paisaje Cultural Cafetero como Patrimonio de la Humanidad. El caso de Caldas).

Esta necesidad de conocimiento situado teje además conexiones con quienes en este tipo de situaciones se han formado en la práctica de manifestarse. Para quien ha vivido de lucha en lucha como sucede a los campesinos del sur del país (Departamentos de Cauca, Nariño, Caquetá), es casi inverosímil imaginar que haya alguien en Colombia que no sepa cómo ponerse en la escena de un paro como estos. Sin embargo, para el centro del país (actuales departamentos de Caldas, Risaralda y Quindío), que durante décadas desde principios del siglo XX y hasta 1987 cuando cae el precio del café y llega la crisis social y económica fue el país de la prosperidad, esto no constituía una necesidad de conocimiento. En la actualidad (luego de la crisis) lo es, y lo que hacen es buscar en quienes tienen la experticia de un conocimiento incorporado de larga data, para formarse con ellos. Lo que describe la persona en la cita no es un caso aislado, viene sucediendo cada vez con mayor frecuencia y mayor profundidad en las pedagogías y didácticas del aprendizaje in situ de las protestas campesinas de esta parte del país, que desde los años 90 dejó de ser el "país aparte» que fue durante la bonanza cafetera ${ }^{11}$.

En este cambio o crisis se puso en evidencia también, que los jornaleros locales, que habían adquirido un largo conocimiento sobre prácticas de producción

10 Cada vez que un entrevistado nos pide omitir su identidad colocamos la sigla IO.

11 Para ampliar esta idea de «territorios en mutación cafetera» véase Nates-Cruz y Velásquez López (2009). 
del café, debían ahora pensar en adquirir otro tipo de conocimiento o de instar a sus nuevas generaciones a aprestarse para adquirirlo. Hacemos referencia sobre todo a la ganadería por ser una actividad opuesta a la agricultura en el escenario y campo expuestos.

Encontramos que los trabajadores que ofrecían sus servicios a fincas-haciendas como la Francia estaban informándose mediante el Servicio Nacional de Aprendizaje (SENA) sobre la oferta de cursos para aprender a inyectar ganado, a aprender de enfermedades, de producción ganadera bovina, entre otros conocimientos. Las poblaciones más jóvenes de tradición campesina están ya en la labor de adquirir estas nuevas exigencias del mercado. Un mercado cuya demanda es mínima y cuya oferta se prepara para ser mucha debido a las expectativas de sustitución de café por ganado en el marco de la crisis del café. Pero lo que está en juego en este fenómeno no es solo el cambio de oficio, lo más importante aquí es el conocimiento y la reestructuración de la organización social que inicia por la familia nuclear y extensa. En las labores de ganadería el papel de la familia ya no es preponderante, las exigencias son mucho menores en términos del tiempo y del espacio. El trabajo con el ganado no requiere allí, de una organización fuerte en número y complejidad, como sí lo requiere el trabajo de la agricultura del café. En la ganadería del lugar solo demandan una mujer para cocinar, uno o dos hombres para cuidar del ganado y algún niño que haga los mandados. El número de trabajadores por finca cambia radicalmente y el rol de la mujer es secundario, la masculinización territorial es evidente y la afectación en el Paisaje Cultural Cafetero (más allá del declaratoria de Paisaje Cultura Cafetero Patrimonio de la Humanidad) es estructural con estas nuevas alternativas. Este cambio en el paisaje se evidencia en temas tan básicos como la distribución y función de la casa, puesto que ya no tiene la centralidad como pasa en la agricultura cafetera. La casa en finca ganadera es más funcional. En la actualidad es usual ver grandes y hermosas casas de antiguas fincas cafeteras desoladas y su rehabilitación es urgente. Los cuarteles o estancias de dormitorios de los trabajadores, las cocinas, los patios, los espacios propios del tratamiento del café, todo está desocupado. La cultura cafetera no es un asunto solo de producción del grano, sino de una cultura construida como conocimiento en práctica, símbolo y discurso. Por tanto, la situación repercute sobre la cohesión territorial local, más allá de la de- cisión de unas fincas, con un fuerte impacto en la relación derecho al territorio y a la justicia cognitiva. Todo en el marco de un problema que, como hemos visto, no solo implica a los jornaleros (visto la entrevista de la finca-hacienda La Gaviota), sino a todo un conglomerado social marginado por la Federación Nacional de Cafeteros que, con la intención expresa de "cooperación para el beneficio de los campesinos», creó un "territorio desmembrado» del resto del país en 1934, con la concupiscencia del Estado Colombiano y los Gobiernos, y que hoy entre los dos, sustentan la Declaratoria de esta zona y algunos municipios más como Paisaje Cultural Cafetero Patrimonio de la Humanidad por la Unesco. Ahora pretenden con ello solucionar la crisis cafetera de la zona, sin mayores apoyos para reactivar una economía basada en la cultura de la producción de café. La ganadería es una sola de las muchas bifurcaciones socioeconómicas que están buscando los campesinos.

\section{REPRESENTACIÓN, RECONOCIMIENTO Y REDISTRIBUCIÓN}

El hecho territorial es lo que marca el establecimiento y la relación en el ciclo que sigue de una a otra de estas escalas culturales (tres R: representación, reconocimiento, redistribución) para pensar la relación derecho al territorio como base de la justicia cognitiva. En esta relación el conocimiento es activo, produce y se deja producir a la manera de la relación entre habitus y hábitat que plantea Pierre Bourdieu (2011), en la cual las producciones y transformaciones surgen de dimensiones y características ecológicas, económicas, culturales, sociales e históricas, pero también de la forma y de la intensidad de la acción.

La representación es uno de los conceptos más potentes en antropología y el de mayor impacto político de todos los conceptos sobre la cultura. La posición y posesión de las cosas, las personas, los actos definen la representación. Así, representar(arse) exige situarse en un lugar y desde allí discurrir y actuar. Ese ejercicio puede igualmente producir un territorio, reconfigurarlo o "ajustarlo» y al realizar cualquiera de estas acciones se construye o "se reconstruye» también el lugar mismo.

La relación entre la posición y posesión de lugar aparece en el trabajo de campo de todos los proyectos que sirvieron como base para este artículo cuando los campesinos nos dicen, por ejemplo, «nosotros 
somos agregados [mayordomos], no somos los dueños, pero conocemos mejor que nadie todo esto, porque de aquí sacamos el pienso [el conocimiento] pa todo lo que decimos que somos y pa todo lo que hacemos de un lado a otro». O cuando se posicionan diciendo: «Nosotros aquí somos codilleros [terrasgueros], lo que queda de la agricultura somos nosotros, todo ahora es potrero. $Y$ aunque todo lo que ve no sea de nosotros, ya no nos lo quitan, ni siquiera el patrón porque esto lo sentimos con el alma» (Entrevistas a don Humberto, agricultor. Potosí Villamaría, agosto de 2012. Proyecto PNNN).

Si la representación da la posición y la posesión, el reconocimiento ofrece la existencia, la de uno y la de los otros con quien debatir, le brinda legitimidad a los actores, a los hechos y a las cosas. El derecho al territorio en escenarios de postconflicto en Colombia bien muestra esta demanda de representación y reconocimiento. Los campesinos del municipio de Pensilvania, Caldas, son un ejemplo de lo que ha pasado en otras partes del país con lo que el gobierno colombiano llama, el Sistema Nacional de Política de Vivienda de Interés Social o Prioritaria ${ }^{12}$. Ellos expresan que no solo deben restituirles un lugar para vivir, sino que también deben reconocerles un lugar de vida al que tienen derecho: «¿Usted vio los apartamentos que hicieron? ni siquiera tenemos fuerzas para subir las escalas, no hay huerta, esa no es casa, es cemento para la paz, ¿esa es la paz? No, nosotros pensamos la paz en nuestras casas, en la cocina que da al patio con una huertecita para poner, aunque sea el cilantro, la cebolla e imaginar con eso que tenemos vida otra vez, sino ¿cómo es que hacen programas como el De Gente en su Tierra? ${ }^{13}$ Sin tierra?» (Entrevista a Rosa María López, campesina desplazada-retornante. Trabajo de Campo. Pensilvania, septiembre de 2015. Proyecto TEMPO). En la Ley de Víctimas y Restitución de Tierras (Ley 1448) citada al comienzo de este artículo, (capítulo IV, artículos 123 y 124) se hace referencia a la restitución de vivienda (otra restitución más, que no lo es según el derecho al territorio tratado aquí).

12 Para ampliar esta información del Sistema ver: <http:// www.minvivienda.gov.co/sobre-el-ministerio/conceptosjuridicos/vivienda-de-inter\%C3\%A9s-social>.

13 Programa de Presidencia de la República de Colombia. Disponible en: <http://www.prosperidadsocial.gov.co/pro/ gd2/Paginas/Familias-en-su-tierra.aspx>. Fecha de acceso: 30 ene. 2017
Según los entes del Estado, se le otorga a cada familia un apoyo equivalente a 22 salarios mínimos legales vigentes para reparación de la vivienda y un apoyo de 60 salarios mínimos legales vigentes para la construcción de vivienda nueva. Lo que en euros es en el primer caso cerca de 4500 y en el segundo 13 000, aproximadamente. Estos montos escasos para reconstruir y hacer de nuevo una vivienda, se suman a los trámites kafkianos y a la sumisión a programas de vivienda preestablecidos como los que describe más arriba la entrevistada de Gente en su Tierra, sin tierra.

En lo expuesto deducimos una mirada cualitativamente diferente que se ocupa de las relaciones de vecindad, alteridad y, con ello, de la cercanía o lejanía cognitiva, con una compleja puesta en escena de material y tecnologías de percepción que permite circunscribir y encuadrar dicho universo y sus modos de configuración y de producción. En lo que queremos poner el énfasis es en la relación entre producción de conocimiento y saberes situados. Esta idea se acerca, de una parte, a la justa restitución interactiva entre representación, reconocimiento y redistribución y, de otra parte, a lo que Foucault denomina el "saber de la gente" y los "saberes sometidos» (2000: 20-23). La restitución de conocimientos y saberes implica, desde la antropología del territorio en particular y desde los estudios territoriales en general, dar validez de existencia a la identidad de lugar en el marco de lo que se conoce como cognitive geopolitics. Pero, además, la justicia cognitiva es el ámbito en el cual se examina cómo influye la diferenciación de saberes y su valoración en la aplicación de conocimientos propios y reapropiados para producir, utilizar y gestionar territorios.

No se trata stricto sensu de qué extensión fisiográfica tenga un lugar (municipio, vereda, pedanía, u otro), ni si cuenta en la escala político-administrativa como de mayor densidad o de mayor producción económica o de equidistancia a la cabecera municipal. Lo que cuenta en esta perspectiva, y a veces exclusivamente, es lo que sucede en el lugar, la fuerza con la que sucede y el impacto que genera; lo que hace que lugares como Pensilvania, Samaná, Ríosucio en Los Andes Colombianos logren entrar en la legitimidad de estas justas demandas con reconocimiento nacional, sin más poder que el ponerse en frente con el reclamo de su producción y gestión de lugares, más allá de las políticas a menudo reduccionistas del Estado colombiano. 


\section{EQUIVALENCIA EPISTEMOLÓGICA EN EL DERECHO AL TERRITORIO Y LA JUSTICIA COGNITIVA}

Entendemos por equivalencia epistemológica las categorías explicativas que como conceptos surgen en una cierta ontología de lugar o que se inspiran en las realidades del lugar, pero van más allá de sus límites espaciotemporales y son susceptibles de ser leídas en realidades múltiples, más allá del mapa euclidiano que distancia los lugares y con ello las realidades.

Pensamos en la equivalencia epistemológica desde lo que Braidotti (2009) denomina transposición que se define como una «transferencia intertextual [que] atraviesa fronteras, transversal en el sentido de un salto, desde un código, un campo o un eje a otro no meramente en el modo cuantitativo de multiplicaciones plurales sino, antes bien, en el sentido cualitativo de multiplicidades complejas [...]. Se crea así una especie de espacio intermedio de zig-zag y cruce: no lineal pero tampoco caótico; nómada y, sin embargo, responsable y comprometido; creativo, pero también cognitivamente válido; discursivo, y también materialmente corporeizado en el conjunto: es coherente sin caer en la racionalidad instrumental» (2009: 20).

Consideramos que en temas como los aquí tratados, resulta importante pensar en modo equivalencia. Conceptos como justicia cognitiva y justicia territorial han sido en las investigaciones referidas ${ }^{14}$, y en otras más, conceptos que traspasan fronteras en culturas colindantes como aquellas a las que se hace referencia en los estudios que dan sustento a este artículo, pero también desde el «norte» al "sur» como pasa con investigaciones que hemos desarrollado en el Norte de España y el Sur de Francia.

En el primer caso de culturas colindantes, parece más allegada la posibilidad de una equivalencia epistemológica en el plano de saberes y conocimientos que producen conceptos para describir y explicar realidades que surgen de dinámicas territorialmente próximas. En el caso segundo, no obstante, lo que hay es que el concepto hace mismidad desde los principios que lo definen, pero se ubica en medios empíricos diferentes porque justamente son procesos históricos diferenciales. Pero en los dos casos, Colombia y Francia, la proximidad en términos de la deman-

14 Ver proyectos en nota inicial del artículo. da de representación, reconocimiento y redistribución es total, aunque el mapa los sitúe en extremos opuestos. Si bien no desconocemos las realidades de toda índole entre uno y otro lugar, el movimiento de hechos y demandas bien pueden trazar nuevos mapas conceptuales que acerquen un mundo con cada vez más pretensiones de ser amurallado.

La aplicación de la justicia territorial implica en las investigaciones realizadas en Colombia que soportan este artículo, el derecho a un saber reconocido (gariteras y bogueadoras del río Chinchiná), la legitimación de una estabilidad sociocultural en tierra propia más allá de las dinámicas de la guerra (indígenas de Ríosucio), la validación de las distintas categorías territoriales tradicionales y de la relación tierra-territorio en contextos de postconflicto como el derecho a recibir restitución en símbolo y políticas (campesinos Pensilvania y Samaná), o la participación territorial diferente, frente a un problema conexo (productores de café en Chinchiná). Sin embargo, como cotejo para ver la posibilidad de funcionamiento de la equivalencia epistemológica en realidades distintas, podemos citar de forma sucinta el trabajo de campo realizado entre 2005-2008 y en 2017 en Saint Antonin Noble Val (departamento del Tarn et Garonne, sur de Francia). Allí encontramos que los pobladores urbanitas que viven ahora en esos pueblos ex-centrados de las urbes, reclaman también una justicia territorial bajo otro sentido: "La culture n'est pas seulement de la ville. Ce n'est pas justice territoriale que le traitement des territoires tel que celui-ci. Je ne trouve pas juste, ni normal que la culture soit réservée aux grandes villes, tout ne se passe pas à Paris» ${ }^{15}$ (Entrevista a la librera Aurèle Letricot. Saint Antonin Noble Val, junio 13 de 2017). Aurèle es propietaria de la única librería de Saint Antonin que ofrece textos sofisticados que van desde arqueología a literatura de los clásicos franceses, pasando por toda una gama de literatura infantil. Esta librería se llama Le tracteur savant (el tractor sabio, letrado, digamos), un título revelador para comprender lo que está diciendo la entrevistada

15 «La cultura no es solamente de la ciudad. No es justicia territorial esa marginación en que se meten territorios como este. No encuentro justo, ni normal que la cultura sea reservada a las grandes ciudades, todo no pasa en Paris (...)» Proyecto Revisite au territoire des anglais dix ans après. Productions territoriales et dynamiques socioculturelles à Saint Antonin Noble Val (département du Tarnet-Garonne). Financiado por la Maison des Sciences de I'Homme, Paris. 
cuando habla exigiendo justicia territorial que en la entrevista materializa la relación derecho al territorio y justicia cognitiva para estos pueblos rururbanos también ubicados al sur del mundo ${ }^{16}$.

Ahora bien, ¿cómo articular esta equivalencia epistemológica con el valor de las escalas culturales? En donde quiera que se ponga en práctica la propuesta de este artículo, deberán tenerse en cuenta los aspectos clave que conciernen a un abordaje de las tres «R», representación, reconocimiento y redistribución. La estructura que correlaciona el derecho al territorio y la justicia cognitiva concierne, en las escalas culturales, a:

1. Los procesos de decisión y no los estados de decisión.

2. La equidad desde el valor sociocultural y político de la igualdad.

3. Los modelos y mejoras de distribución espacial de la riqueza material y de las oportunidades como base de la experiencia.

4. La distribución en cuando al acceso a bienes materiales e inmateriales donde cuenta la posición socioespacial de los actores.

5. La exploración y repartición de las prácticas y discursos espaciales en cuanto al control y vivencia por parte de distintos actores con el fin de hacer evidentes las formas veladas de dominación.

$\mathrm{Y}$, por tanto, entender, y sobre todo asumir, que las escalas de la geografía económica: distancia, división y densidad (tres $\mathrm{D}$ ), deben entran en diálogo con las escalas como valor o escalas culturales (las tres $\mathrm{R}$ ). $\mathrm{Si}$ tenemos en cuenta que las escalas son en su naturaleza una medida, debemos preguntarnos entonces qué queremos medir y sobre todo desde dónde queremos o debemos medirlo. No es posible que mientras el conteo del mundo se pone en el plano de quienes producen más, o cómo entran en el concierto de cercanía o lejanía del poder, o qué tienen para ser ponderados según interese hegemónicos, los lugares mismos sean subsumidos sin que haya modos de comprometerse activamente con sus presentes. 0 como diría Braidotti (2015), sin que seamos capaces de concebir nuevos esquemas sociales, éticos y discursivos para afrontar los profundos cambios a los que nos enfrentamos.

16 Para ampliar este caso de Aurèle véase <https://www.youtube.com/watch?v=SOkboc9U66l>.

\section{CINCO NOTAS PARA UN POSIBLE CIERRE}

1. Reconsiderar la concepción derecho-cognición en el marco de las escalas culturales para analizar problemas territoriales multidimensionales, lo que implica ajustar, también, las herramientas conceptuales con las cuales estamos estudiando y participando de su transformación.

2. El derecho al territorio es un poder explicativo que emerge desde la concepción y aplicación de la justicia.

3. El territorio como medio explicativo práctico y discursivo para pensar y ejercer la justicia (cognitiva y territorial) debe ser un objetivo de la acción social democrática.

4. Desde las dinámicas contemporáneas debe darse la des-segregación del territorio a donde se lo ha confinado designándolo como lo que «está en otra parte». Esta des-segregación permitiría superar la concepción del territorio como un simple contenedor de hechos y discursos a lo que lo ha reducido a menudo la antropología y lo pondría, entonces, en donde debe estar como la mayor fuerza de la acción sociocultural. En este ejercicio de des-segregación, la justicia cognitiva debe reconocer la exploración y repartición de las prácticas y de los discursos espaciales en cuanto al control y vivencia de los espacios de vida y los espacios vividos.

5. El estudio del derecho al territorio como base de la justicia cognitiva debe tratarse desde una equivalencia epistemológica que permita leer realidades múltiples para generar una especie de espacio intermedio cognitivamente válido y corporeizado en su conjunto, que permita acercar lo que la globalidad contemporánea se ha empeñado en separar. Para nuestro caso es factible pensar, desde la equivalencia epistemológica, en la conexión de lugares tanto conexos como disociados: los Andes centrales de Colombia o el sur de Francia, haciendo el ejercicio de pensar en el derecho al territorio como el nuevo derecho humano y como un marco de acción colectiva.

\section{BIBLIOGRAFÍA CITADA}

Berardi-Tadié, Barbara 2017. L'ère des droits: vers une anthropologie des associations de la société civile au Népal. París: EHESS. 
Bocarejo Suescún, Diana. 2011. «La movilización política de espacios imaginados: nuevas fronteras indígenas y campesinas», en Margarita Chaves (comp.), Indígenas, afrodescendientes. La multiculturalidad estatalizada: 151-160. Bogotá: Instituto Colombiano de Antropología e Historia (ICAHN)

Bocarejo Suescún, Diana. 2015. «An Ordinary Peace in a Disparate Landscape of Longings». Hot Spots, Fieldsights, April 30. Society for Cultural Anthropology. <https://culanth.org/ fieldsights/an-ordinary-peace-in-a-disparate-landscape-oflongings>.

Bolívar Jaime, Aura, Angie Paola Botero Giraldo y Laura Gabriela Gutiérrez Baquero. 2017. Restitución de tierras, política de vivienda y proyectos productivos. Ideas para el posacuerdo. Bogotá: Colección DEJUSTICIA.

Bolívar Jaime, Aura, Nelson Camilo Sánchez León y Rodrigo Uprimny. 2017. Debates sobre la acción de restitución. Bogotá: Colección DEJUSTICIA.

Bourdieu, Pierre. 2003. «Participant objetivation». Journal of The Royal Anthropological Institute 9(2): 281-294. doi: <https://doi.org/10.1111/1467-9655.00150>.

Bourdieu, Pierre. 2011. Pierre Bourdieu en Argelia. Imágenes del desarraigo. Edición de Franz Schultheis \& Christine Frisinghelli. Madrid: Círculo de Bellas Artes.

Braidotti, Rosi. 2005. Metamorfosis. Hacia una teoría materialista del devenir. Madrid: Akal.

Braidotti, Rosi. 2009. Transposiciones. Sobre la ética nómada. Barcelona: Gedisa

Braidotti, Rosi. 2015. Lo posthumano. Barcelona: Gedisa

CINEP. 2009. Derecho a la tierra y al territorio. Bogotá: CINEP.

Claeys, Priscilla. 2016. The right to land and territory: New human right and collective action frame. París: Fondation Maison des sciences de l'homme. FMSH-WP-2016-109. Disponible en: <https://halshs.archives-ouvertes.fr/halshs-01316857/document>. Fecha de acceso: 2 feb. 2018.

Colombia. 2011. Ley 1448. Ley de Víctimas y Restitución de Tierras. Bogotá: Gobierno de la República de Colombia.

Comisión Colombiana de Juristas. 2011. Informe sobre la situación del derecho al territorio de los pueblos indígenas y las comunidades afrodescendientes en Colombia. Bogotá: CCJ.

Comisión Nacional de Reparación y Reconciliación. 2009. El despojo de tierras y territorios. Aproximación conceptual. Bogotá: CNMH-IEPRI.

Coronado Delgado, Sergio Andrés. 2006. «El territorio: derecho fundamental de las comunidades afrodescendientes en Colombia». Revista Controversia 187: 48-81.

Fernandes, Bernardo Mançano. 2008a. «Questão Agraria: conflictualidade e desenvolvimento territorial», en A. M. Buainain (ed.), Luta pela Terra, Reforma Agraria e Gestão de Conflitos no Brasil: 173-224. Campinas: UNICAMP.

Fernandes, Bernardo Mançano. 2008b. «Entrando nos territórios do território», en E. T. Paulino y J. E. Fabrini (eds.), Campesinato e territórios em disputas: 273-301. São Paulo: Expressaão Popular.
Fernandes, Bernardo Mançano. 2009. «Território, teoria y política», en Georgina Calderón y Efraín León (coords.), Descubriendo la espacialidad social en América Latina. Colección Cómo pensar la geografía: Vol. 3. México: Editorial Itaca.

Foucault, Michel. 2000. Defender la sociedad. México: Fondo de Cultura Económica.

Fraser, Nancy. 2008. Escalas de justicia. Barcelona: Herder.

Haesbaert, Rogerio. 2011. El mito de la desterritorialización: del fin de los territorios a la multiterritorialidad. México: Siglo XXI.

Haraway, Danna. 1995. Ciencia, cyborgs y mujeres. La reinvención de la naturaleza. Madrid: Cátedra.

Haraway, Danna. 1997. Modest_Witness@Second_Millennium. FemaleMan_Meets_OncoMouse: Feminism and Technoscience. Nueva York/Londres: Routledge.

Harvey, David. 2013. Ciudades rebeldes. Del derecho a la ciudad a la revolución urbana. Madrid: Akal.

Hayot, Alain. 2004. «Pour une anthropologie de la ville et dans la ville : questions de méthodes». Revue Européenne des Migrations Internationales 18(3): 93-105. doi: <https://doi. org/10.4000/remi.2646>.

Ignatieff, Michael. 2018. Las virtudes cotidianas. El orden moral en un mundo dividido. Barcelona: Taurus.

LVC = La Vía Campesina. 2012. Discurso de La Vía Campesina para el Foro Campesino. Roma: LVC. Disponible en: <https:// viacampesina.org/es/discurso-de-la-via-campesina-para-elforo-campesino-2012/>. Fecha de acceso: 30 ene. 2018.

Lefebvre, Henri. 1975. El derecho a la ciudad. Barcelona: Península.

Letricot, Aurèle. 2017. Librairie Le Tracteur Savant. Entrevista. Disponible en: <https://www.youtube.com/ watch?v=SOkboc9U66I>. Fecha de acceso: 15 jun. 2017.

Lévi-Strauss, Claude. 1998. Tristes trópicos. Buenos Aires: Paidós

Martin, Julien y Olivier Renaudie. 2017. «Un droit au territoire? Retour sur quelques malentendus». Civitas Europa 38: 201220. Disponible en: <https://www.cairn.info/revue-civitaseuropa-2017-1-p-201.htm>. Fecha de acceso: 10 feb. 2018.

Martínez-Calderón, Camila. 2014. Reparación integral en el campo desde procesos de territorialización de la memoria. Una mirada desde el derecho. Estudio aplicado en Samaná, Pensilvania, La Dorada y Aguadas (Caldas, Colombia). Manizales: Universidad de Caldas, Proyecto TEMPO (UCALDASCNMH-COLCIENCIAS-RETEC).

Massey, Doreen. 2005. For Space. Londres: Sage Publications

Mate, Reyes. 2011. Tratado de la injusticia. Barcelona: Anthropos, Editorial.

Nates, Béatriz. 2016a. «Geografías de la civilidad. Prácticas y discursos territoriales en escenarios de postconflicto en Colombia». Psicología desde el Caribe 33: 81-96. doi: <https:// doi.org/10.14482/psdc.33.1.8078>. 
Nates, Béatriz. 2016b. «Los lugares, el lugar de la antropología del territorio en Colombia», en Jairo Tocancipá-Falla (coord.), Antropologías en Colombia: tendencias y debates actuales: 393-448 Popayán: Ediciones Universidad del Cauca.

Nates, Béatriz. 2018a. «Aportes epistemológicos y políticos de la antropología al estudio de las escalas territoriales», en Ernesto Licona Valencia (coord.), Espacialidades. Puebla: Universidad de Puebla.

Nates, Béatriz. 2018b. «Cambio de escalas y rururbanidades contemporáneas geografías de la civilidad en pueblos de montaña, Colombia», en Foro internacional de municipios de montaña. La montaña y el derecho al desarrollo. Fez, Marruecos: Coalition Civile pour la Montage.

Nates, Béatriz. 2018c. "Derecho y conocimiento territorial», en 2da. jornada internacional Cultura-Naturaleza. Perspectivas y debates espacio-temporales en torno a la apropiación de la naturaleza. Santiago de Chile: Universidad Católica de Chile-Universidad de Chile.

Nates, Béatriz. 2019. "Lugarización y territorialización de la civilidad. Etnografías transversales», en Jornadas del Programa Territorio, Naturaleza, Cultura. Buenos Aires: Facultad de Letras de la Universidad de Buenos Aires.

Nates-Cruz, Béatriz y Paula Andrea Velásquez López. 2009. «Territorios en mutación. Crisis cafetera, crisis del café». Cuadernos de Desarrollo Rural 6(63): 11-33.

Nates-Cruz, Béatriz, Paula Andrea, Velásquez López y María García Alonso. 2018. La territorialización de la memoria en escenarios de postconflicto. Manizales: CNMH, COLCIENCIAS, UCALDAS, RETEC.
Novoa, Edgar. 2016. Geografías de la diferencia, espacialidad, política y acción social. Bogotá: Universidad Nacional.

OIT. 1989. Convenio no. 169. Ginebra: OIT.

Pérez Trujillo, María Fernanda y Jaime Landínez Aceros. 2018. Catatumbo: memorias de vida y dignidad. Bogotá: Centro Nacional de Memoria Histórica.

Rappaport, Joanne. 2000. La política de la memoria. Interpretación indígena de la historia en Los Andes Colombianos. Popayán: Editorial Universidad del Cauca.

Revista SEMANA. 2013. Paro Agrario, las dos caras de la protesta. Disponible en: <http://www.semana.com/nacion/articulo/paro-agrario-las-dos-caras-de-la-protesta/>. Fecha de acceso: 3 jul. 2014.

Rincón, John Jairo. 2017. Crecer como un río. Volumen I. Bogotá: Centro Nacional de Memoria Histórica.

Rodríguez, Gloria Amparo. 2010. La consulta previa con pueblos indígenas y comunidades. Bogotá: Universidad del Rosario.

Rousseaux, Francis y Jean Petit. 2014. «Une analyse anthropologique des mutations territoriales». URBIA. Les Cahiers du développement urbain durable 16: 211-228. Disponible en <https://hal.archives-ouvertes.fr/hal-01084766>. Fecha de acceso: 10 mar. 2018.

Sánchez León, Nelson Camilo. 2017. Tierra en transición. Justicia transicional, restitución de tierras y política agraria en Colombia. Bogotá: Colección DEJUSTICIA.

Verdier, Raymond. 1981. «Un domaine à explorer, l'anthropologie du droit». Bulletin de l'Association française des anthropologues 4: 29-32.

Young, Marion. 2011. Responsabilidad con justicia. Madrid: Morata Ediciones. 